\title{
High performance organic field-effect transistors with a solid and aqueous dielectric based on a solution sheared sulfur-bridged annulene derivative
}

Antonio Campos, Qiaoming Zhang, M.R. Ajayakumar, Francesca Leonardi and Marta Mas-Torrent

\author{
A. Campos, Q. Zhang, Dr. M.R. Ajayakumar, Dr. F. Leonardi, Dr. M. Mas-Torrent \\ Institut de Ciència de Materials de Barcelona (ICMAB-CSIC) and Networking Research \\ Center on Bioengineering, Biomaterials and Nanomedicine (CIBER-BBN) \\ Campus UAB, Cerdanyola del Vallès, 08193 Barcelona, Spain \\ E-mail:mmas@icmab.es
}

Keywords: Organic semiconductor:polymer blends, Solution shearing techniques, Barassisted meniscus shearing, Electrolyte-gated field-effect transistors, Organic field-effect transistors.

Thin films of the organic semiconductor meso-diphenyl tetrathia[22]annulene[2,1,2,1] (DPTTA) have been prepared for first time employing solution-based techniques to fabricate organic field-effect transistors (OFETs). Homogeneous and crystalline films of this semiconductor have been achieved thanks to the synergic approach of employing blends of this material with polystyrene (PS) and the high throughput technique Bar-Assisted Meniscus Shearing (BAMS) with a hydrophobic bar. The resulting active layers exhibit state-of-the-art OFET performance with an average mobility of $1 \mathrm{~cm}^{2} / \mathrm{V} \cdot \mathrm{s}$, threshold voltage close to $0 \mathrm{~V}$, high on/off ratio and sharp switch on. Furthermore, a DPTTA:PS formulation has been optimized to prepare films suitable for their integration in electrolyte-gated field effect transistors (EGOFET) operating in ultrapure water and a $0.5 \mathrm{M} \mathrm{NaCl}$ aqueous solution. Such devices also reveal excellent performance with mobility values above $0.1 \mathrm{~cm}^{2} / \mathrm{V} \cdot \mathrm{s}$, potentiometric sensitivity $\sim 200 \mu \mathrm{V}$, time response $\sim 9 \mathrm{~ms}$ and long term stability in ultrapure water. Hence, this work supports the strategy of combining organic semiconductor:polymer blends with BAMS as a powerful route for achieving high performing 
devices, and also points out DPTTA as a highly promising material to be integrated in organic electronic devices.

\section{Introduction}

One of the current major challenges in organic electronics is the production of devices that can compete with amorphous silicon-based technology in terms of materials and processing costs, scalability of the fabrication process and compatibility with flexible substrates. Within this regard, organic semiconductors (OSC) are an advantageous choice because potentially they can be processed from solution-based techniques and they are compatible with a plethora of materials ranging from metals to biodegradable polymers. ${ }^{[1]}$ Several examples in the fields of sensors, memory devices and cheap disposable electronics ${ }^{[2-4]}$ have already demonstrated the potential of organic electronics in replacing conventional inorganic-based technologies. The ideal electrical characteristics in organic materials are typically only found in single crystals of small conjugated molecular OSCs. ${ }^{[5]}$ However, tiresome growth and manipulation of these hamper their practical implementation. Hence, to further progress towards the development of organic electronics, it is imperative to: i) synthesize promising soluble organic semiconductors exhibiting state-of-the-art mobilities $(\mu),{ }^{[6-8]}$ and ii) develop low-cost processing techniques compatible with up-scaling and high throughput processes that can lead to crystalline and homogenous thin films with high reproducibility. ${ }^{[9-13]}$

One promising approach devoted to facilitating thin film processability of OSCs is based on employing solutions of the OSC with binding polymers. ${ }^{[14-17]}$ Thin films prepared from such kind of blends have often displayed a superior electrical performance compared to the pristine OSC film once integrated in electronic devices due to an enhanced crystallinity of the organic molecule and improved device stability towards adventitious agents. Recently our group demonstrated the superior advantages of processing such kind of blends through a 
shearing technique called Bar-Assisted Meniscus Shearing (BAMS). ${ }^{[18,19]}$ This strategy has revealed to be a powerful method for fabricating organic field-effect transistors (OFETs) with excellent performances $^{[9]}$ and, moreover, the devices displayed an improved water stability due to the self-encapsulation capability imparted by the process itself. ${ }^{[18,20]}$ This complementary approach encourages its application in novel OSCs that could take advantage from this methodology.

Recently, the p-type semiconductor meso-diphenyl tetrathia[22]annulene[2,1,2,1] (DPTTA) (Scheme 1) has been reported to exhibit a fairly good field-effect mobility of 0.7 $\mathrm{cm}^{2} / \mathrm{V} \cdot \mathrm{s}$ as single-crystal OFET and a mobility of $0.29 \mathrm{~cm}^{2} / \mathrm{V} \cdot \mathrm{s}$ as evaporated thin film OFET. ${ }^{[21]}$ The study of the electrical properties of single crystals and thermally evaporated thin films of OSC has always represented two perfect tools for testing new organic materials. DPTTA has also been exploited as the donor component in donor/acceptor cocrystals, some of which exhibited ambipolar characteristics with high hole and electron mobilities. ${ }^{[22,23]}$ Despite the high potential of this material as active component in devices, to the best of our knowledge, it has not been processed yet in thin film by any solution-based processing technique, which clearly hinders its applicability into real devices.

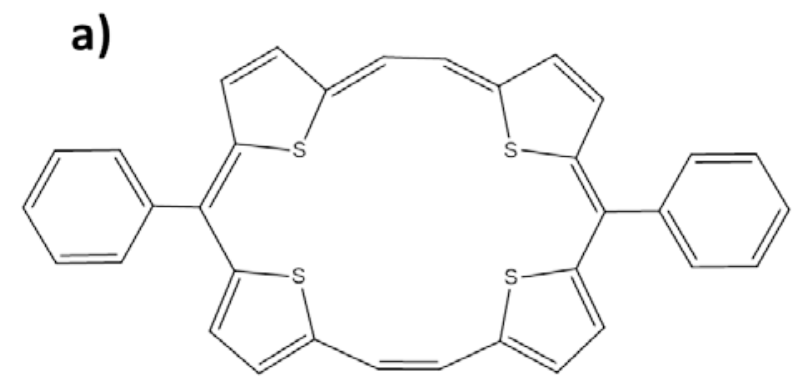

b)

Scheme 1. Chemical structure of a) DPTTA and b) PS.

Our goal is to shed new light on this quite uncharted semiconductor with respect to its processability as thin film employing a solution shearing technique, i.e. BAMS. The first part 
of the work aims to optimize the blend composition of DPTTA with polystyrene (PS) by varying the ink formulation. This screening allowed us to achieve DPTTA-based thin film OFETs having an average mobility values around $1 \mathrm{~cm}^{2} / \mathrm{V} \cdot \mathrm{s}$, positioning this material among the best benchmark OSCs. Notably, the resulting electrical performance is even superior to the single-crystal based OFET already reported in literature. ${ }^{[21]}$ Additionally, since wide ranging opportunities for OFETs are open in sensing applications, the fabricated DPTTA films have been further tested in aqueous media using the so-called Electrolyte-Gated Organic Field-Effect Transistors (EGOFET) configuration. ${ }^{[24]}$ EGOFETs layout consists of exposing directly the semiconductor towards an aqueous media which acts as a dielectric, as depicted in Figure 1b. Since these devices can operate in water, they can be directly adapted for the development of chemical or biochemical sensors. We demonstrate that DPTTA:PS films can also be successfully integrated in EGOFETs giving state-of-the-art performances. ${ }^{[25,26]}$ Hence, this work evidences the inner potential of our approach for the fabrication of disposable electronics.

a)

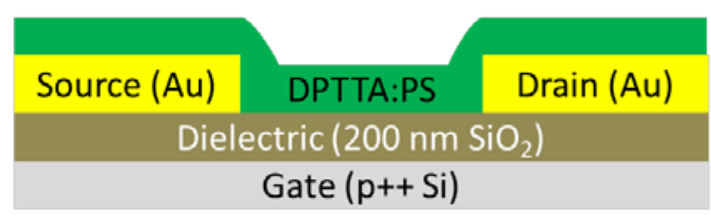

b)

Gate (Pt wire)

PDMS water

container

Figure 1. a) Bottom-gate bottom-contact OFET and (b) top-gate bottom-contact EGOFET configurations used in this work.

\section{Results and Discussion}

\subsection{Active Layer Fabrication and Characterization}


DPTTA is a quite unexplored semiconductor in the organic electronic panorama and, to our knowledge, there are no precedents of devices fabricated from solutions of DPTTA. Films processed by BAMS of pure DPTTA were tested but, due to the low solubility of the material and the low viscosity of the solution, the films obtained were not homogenous. Hence, for the thin film processing of this material it was required to blend it with polymers, in this case PS. It is also worth mentioning here, that the vertical phase separation that usually takes place in these blends, ${ }^{[20,27-30]}$ improves the OSC/dielectric interface since the PS passivates the dielectric surface resulting in devices revealing a lower density of traps.

Films based on DPTTA and PS blend solutions in chlorobenzene were deposited using different ratios of OSC:PS (1:2, 1:3 and 1:4) and PS with different molecular weight (3k, 10k and $100 \mathrm{k}$ g/mol, namely PS 3k, PS 10k and PS 100K, respectively) with a concentration in the range 1.8-2.3\% wt. (see Experimental Section). In all the formulations tested the concentration of DPTTA could not exceed $7.5 \mathrm{mg} / \mathrm{ml}$ due to the limited solubility of the OSC. As previously mentioned, all films have been prepared using the BAMS technique. ${ }^{[18]}$ The conventional BAMS setup requires the use of a metallic bar so that the OSC solution can form a meniscus between it and the target heated substrate. Subsequently, the bar is displaced at a specific speed. However, our first attempts for preparing coatings based on DPTTA:PS on $\mathrm{Si} / \mathrm{SiO}_{\mathrm{x}}$ substrates failed since, as depicted in Figure $\mathrm{S} 1$, the resulting thin films were not crystalline. Interestingly, when the metallic bar was changed for a polytetrafluoroethylene (PTFE) one, a homogeneous polycrystalline film was obtained (Figure 2). This is not the first time that changing the surface energy of the shearing component has an impact on the resulting film. For instance, Giri et al. reported an increase in the OFET performance when the solution was sheared using an OTS-modified plate (OTS stands for octadecyltrichlorosilane) for depositing the organic semiconductor. ${ }^{[31]}$ Even though the insight of this interesting effect is beyond the scope of the present work, a possible change in the 
meniscus shape due to the hydrophobicity of the bar is the most probable reason for the two different behaviors observed in the present case. In all the experiments, the substrate temperature and the bar speed was set to be $105{ }^{\circ} \mathrm{C}$ and $10 \mathrm{~mm} / \mathrm{s}$, respectively. The fine control of the above mentioned experimental conditions and a pre-heating of the blend solution to avoid material precipitation are fundamental requirements for obtaining good coatings with high reproducibility and a small device-to device variation in terms of electrical performance.

As already anticipated, DPTTA:PS blends have been tested as active material in two kind of devices; i) Bottom Gate/Bottom Contact (BG/BC) OFETs (Figure 1a) and ii) EGOFETs (Figure 1b). Regarding bottom gate/bottom contact OFET the optimal formulations were: DPTTA:PS (1) 1:3 (PS 3k), (2) 1:2 (PS 10k) and (3) 1:2 (PS 100k) (Table 1). On the other hand, for EGOFET fabrication, the optimized formulation is (4) 1:3 (PS 10k) (Table 1). This formulation works better as EGOFET probably due to the presence of a PS encapsulating layer that protects the OSC better preventing a rapid degradation of the DPTTA when it is in direct contact with water. It should also be mentioned here that the best performing devices were realized functionalizing the source and drain gold electrodes with a self-assembled monolayer (SAM) of pentafluorothiophenol (PFBT).

In Figure 2, the optical and atomic force microscopy (AFM) images of the thin films prepared with the optimized formulations are shown. Clearly, the deposited thin films exhibit a different film growth on the Au/PFBT electrodes and on the silicon oxide substrate. In the channel area crystalline domains are observed formed by wave-like microstructures which increase the roughness of the films. The roughness of the active layers, quantified with the root mean square roughness $\left(\delta_{\mathrm{RMS}}\right)$, were found to be higher in films prepared from blends 2 $\left(\delta_{\mathrm{RMS}}=16.78 \mathrm{~nm}\right)$ and $4\left(\delta_{\mathrm{RMS}}=15.48 \mathrm{~nm}\right)$, while smoother films resulted from formulations $3\left(\delta_{\mathrm{RMS}}=4.96 \mathrm{~nm}\right)$ and $1\left(\delta_{\mathrm{RMS}}\right.$ of $\left.6.95 \mathrm{~nm}\right)$. However, on the Au/PBFT source/drain electrodes modified neither large crystallites nor wave-like microstructures on top are 
observed. Notably, the AFM phase image shows that there is no a visible change in the surface energy between the film on the silicon oxide and on Au/PFBT (Figure S2), suggesting that both the electrodes and the active layer are covered by a PS encapsulating layer.

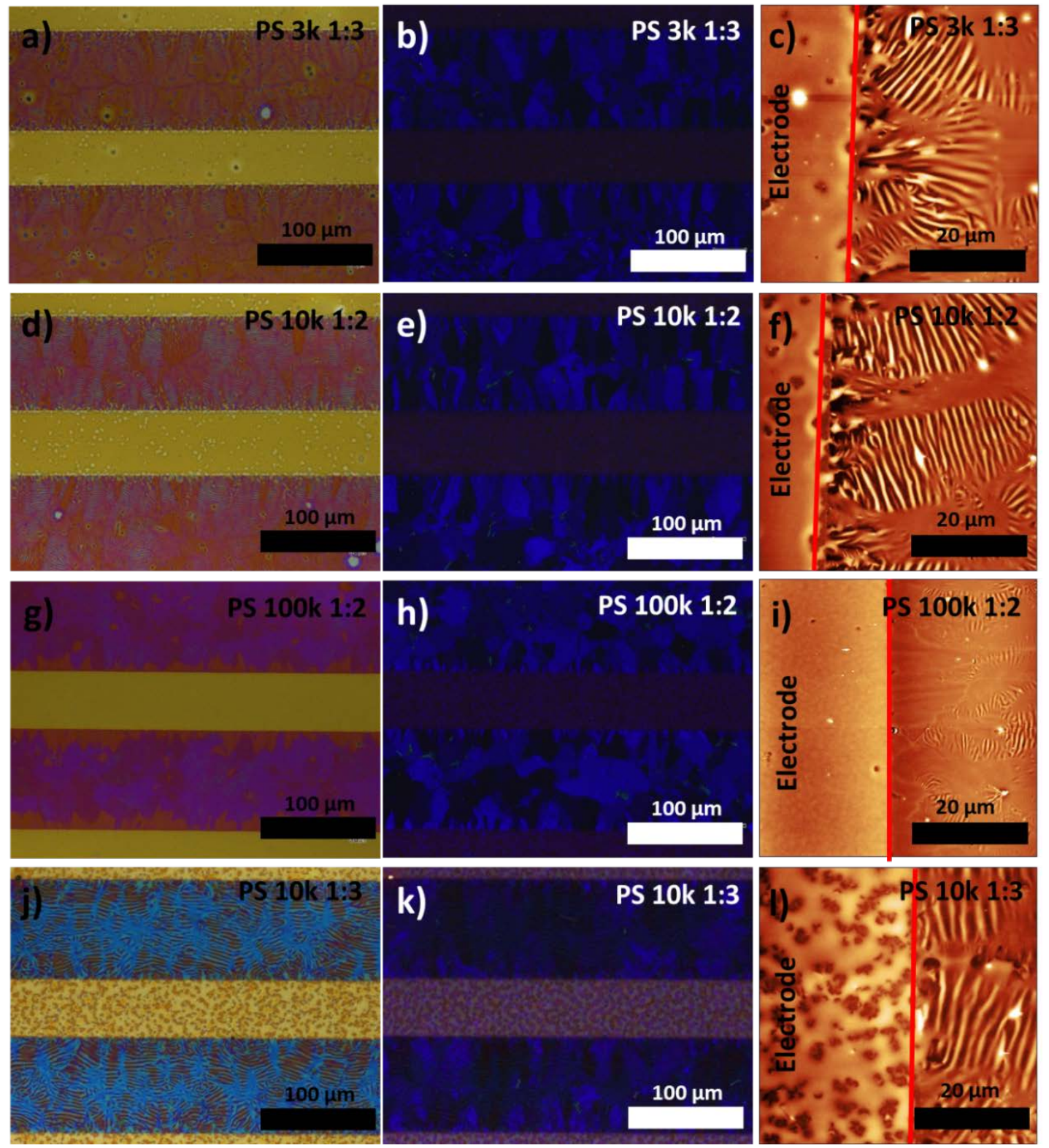

Figure 2. Images of the different optimized films obtained by a), d), g) and j) optical microscope, b), e), h) and k) polarized optical microscope and c), f), i) and l) AFM. Scale bars correspond to 100 and $20 \mu \mathrm{m}$ in optical microscope and AFM images, respectively. In the AFM images the edge of the Au/PFBT electrodes is drawn to highlight the different film growth. 
X-ray powder diffraction (XRPD) analysis of the films confirmed that all the films belong to the same crystalline phase (Figure S3). Additionally, the crystalline phase observed

in the films does not seem to correspond to the reported one for the single crystal. ${ }^{[21]}$ The reflections cannot be associated to any $(00 \mathrm{n})$ crystallographic plane due to the lack of periodicity in the peaks spacing in the diffractogram. This indicates that the crystals are not oriented with respect to the substrate, which could be expected because of the wave-like microstructure of the film. This different polymorph of DPTTA may be associated to a surface promoted growth as it has been commonly observed in other OSCs such as in tetrathiafulvalene derivatives. ${ }^{[32-35]}$

\subsection{OFET Electrical Characterization}

In order to evaluate the OFET electrical characteristics of all DPTTA:PS films, a $\mathrm{BG} / \mathrm{BC}$ configuration using the $\mathrm{Si} / \mathrm{SiO}_{\mathrm{x}}$ as gate/gate dielectric was used for the initial formulation screening (Figure 1a). All the measurements were performed under ambient conditions. As reported in Figure 3, all transfer and output characteristics show a clear p-type behavior in all the devices in a gate-source voltage $\left(V_{G S}\right)$ window ranging from 10 to $-20 \mathrm{~V}$. The extracted field-effect mobility in saturation regime $\left(\mu_{F E \text { sat }}\right)$, threshold voltage $\left(V_{T H}\right)$, subthreshold slope (SS) and on/off current ratio $\left(I_{o n /} I_{\text {off }}\right)$ are summarized in Table 1. All devices exhibited a rather high average field effect mobility above $0.5 \mathrm{~cm}^{2} / \mathrm{V} \cdot \mathrm{s}$. Remarkably, the OFETs fabricated with the formulation 2 showed an average mobility of $\sim 1 \mathrm{~cm}^{2} / \mathrm{V} \cdot \mathrm{s}$ with a maximum value of $1.21 \mathrm{~cm}^{2} / \mathrm{V} \cdot \mathrm{s}$. Even though this $\mu_{\mathrm{FE} \text {,sat }}$ overcomes the value found for the single crystal $\left(0.7 \mathrm{~cm}^{2} / \mathrm{V} \cdot \mathrm{s}\right)$, it should be kept in mind that the polymorph found in these thin films is different from the single crystal polymorph. Hence, without the resolved crystal structure, we can only anticipate that the new polymorph discovered in this work should be 
more suitable for electronic transport. It should be also noticed that employing this fast deposition technique the benchmark high performing OSCs 6,13bis(triisopropylsilylethinyl)pentacene $\quad$ (TIPS-PEN) and 2,8-difluoro-5,11bis(triethylsilylethynyl)anthradithiophene (diF-TES-ADT) gave average mobilities of the same order. ${ }^{[9]}$

The high performance of the fabricated devices is further evidenced by the threshold voltage close to $0 \mathrm{~V}$, the sharp switch on represented by a small sub-threshold swing, the low contact resistance visible with the linearity of the output curves, and the lack of hysteresis. Importantly, the sharp switch on and the almost zero hysteresis suggest a low trap density in these films. ${ }^{[36-39]}$ The trap density values were estimated in the sub-threshold regime (see experimental section for details). Trap density $\left(N_{T}\right)$ values in the range from $1.2 \cdot 10^{12}$ down to 3.6 $10^{11} \mathrm{eV}^{-1} \cdot \mathrm{cm}^{-2}$ were found for the different DPTTA:PS formulations investigated (Table 1), being the films with lower trap density the one prepared employing a higher molecular weight PS (formulation 3) and the one with a higher proportion of PS with respect to OSC (formulation 4). It should be highlighted that these values are comparable to the ones reported by Amassian et al. for similar films based on blends of the OSC dif-TES-ADT with PS exhibiting crystal-like electrical performance. ${ }^{[16]}$ This low density of traps can be explained, as previously mentioned, by the vertical phase separation that takes place during the crystallization. This promotes the growth of the polycrystalline layer of DPTTA on top of a PS layer that acts as a buffer layer avoiding the charge trapping in the polar hydroxyl groups present at the interface with the $\mathrm{SiO}_{\mathrm{x}}$ dielectric. In addition, although all the mobility profiles are not completely independent of the gate voltage, there is not any sharp peak, which could be indicative of a significant contact resistance and could lead to an overestimation in the mobility calculation. ${ }^{[40]}$ 

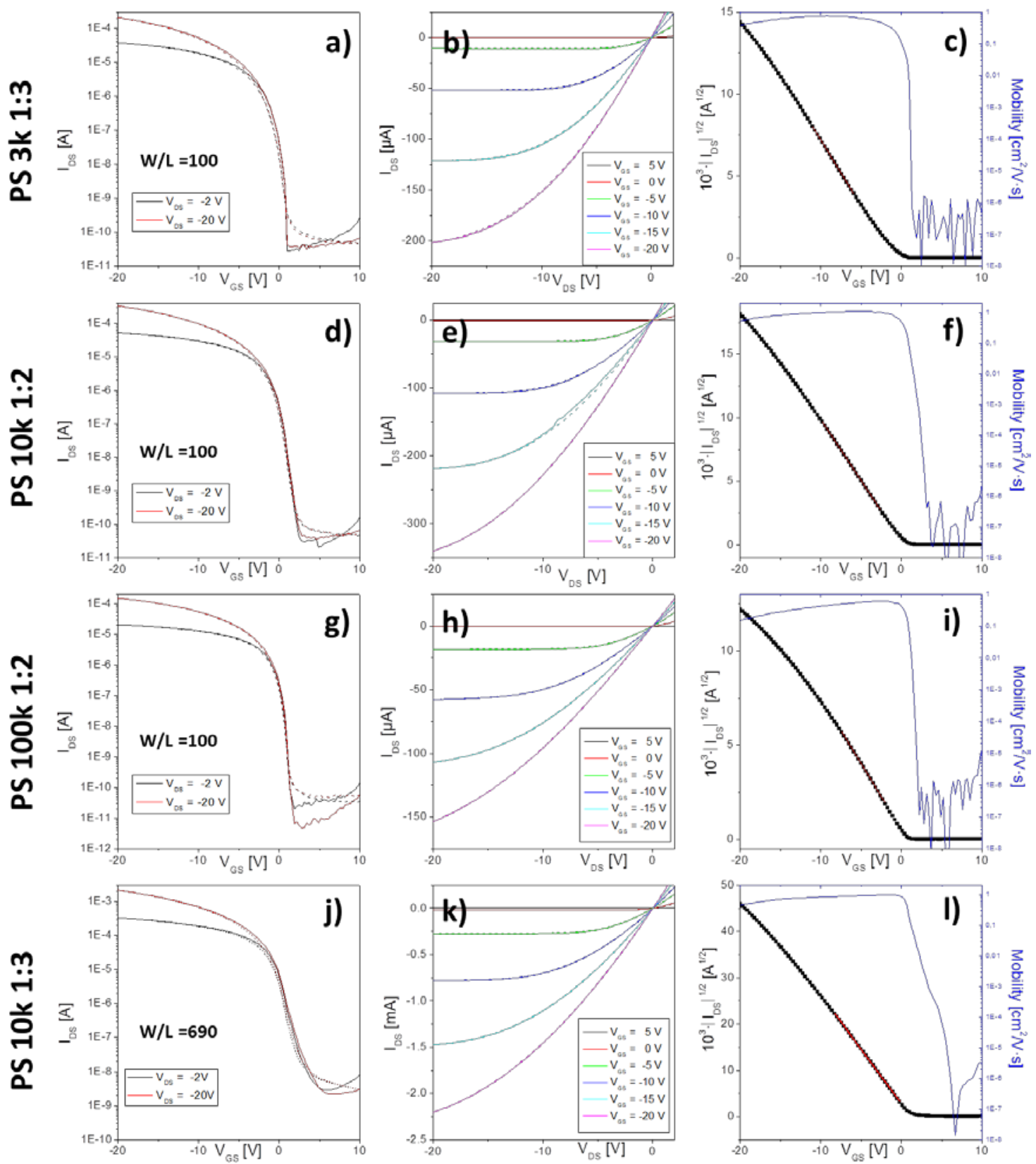

Figure 3. Transfer a), d), g) and j) and output b), e), h) and $\mathbf{k}$ ) characteristics of the OFETs prepared from the formulations indicated on the left. Dashed lines are used to indicate the reverse scan in both transfer and output characteristics. c), f), i) and l) are the mobility profile and the square root of the absolute value of the source-drain current vs. source-gate voltage. The linear fit used to calculate the mobility is shown with a red line. 
Table 1. OFET parameters found in DPTTA for the different blend formulations. The reported values are the average out of 24 transistors for formulation $\mathbf{1}$ and 3, 48 transistors for 2 and 96 for 4 . Values in parenthesis correspond to the best value found for each specific condition.

\begin{tabular}{|c|c|c|c|c|c|}
\hline & Solution & 1 & 2 & 3 & 4 \\
\hline \multirow{3}{*}{ 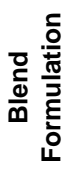 } & Polymer & PS 3k & PS 10k & PS 100k & PS 10k \\
\hline & Ratio [OSC:Polymer] & $1: 3$ & $1: 2$ & $1: 2$ & $1: 3$ \\
\hline & Concentration $[\mathrm{mg} / \mathrm{ml}]$ & 26 & 22.6 & 22.6 & 20 \\
\hline \multirow{6}{*}{ 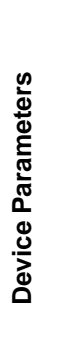 } & $\mu_{F E, s a t}\left[\mathrm{~cm}^{2} / \mathrm{V} \cdot \mathrm{s}\right]$ & $0.57(0.64)$ & $1.03(1.21)$ & $0.55(0.68)$ & $0.67(1.00)$ \\
\hline & $\mu_{d} / \mu_{\text {average }}[\%]$ & 9.3 & 12.3 & 18.0 & 25.5 \\
\hline & $V_{T H}[\mathrm{~V}]$ & 0.47 & -0.02 & 0.34 & 0.86 \\
\hline & S.S. [V/dec] & $0.70(0.35)$ & $0.70(0.50)$ & $0.26(0.21)$ & $0.41(0.36)$ \\
\hline & $N_{T}\left[\mathrm{eV}^{-1} \mathrm{~cm}^{-2}\right]$ & $1.2 \cdot 10^{12}$ & $1.2 \cdot 10^{12}$ & $3.6 \cdot 10^{11}$ & $6.3 \cdot 10^{11}$ \\
\hline & $I_{o n} / I_{\text {off }}$ & $5.1(6.3) \cdot 10^{6}$ & $4.5(9.7) \cdot 10^{6}$ & $1.1(3.0) \cdot 10^{7}$ & $6.5(16) \cdot 10^{5}$ \\
\hline
\end{tabular}

\subsection{EGOFET Electrical Characterization}

In an EGOFET configuration the aqueous media acts as the effective gate dielectric. The two Electrical Double Layers (EDLs) at the top gate/electrolyte and electrolyte/OSC interfaces bear a capacitance in the order of tens of $\mu \mathrm{F} / \mathrm{cm}^{2}$ compared to $\mathrm{nF} / \mathrm{cm}^{2}$ of standard dielectrics, which ensures low voltage operation. Finding stable OSC films in this media is crucial for the progress of EGOFETs. Undoubtedly, the choice of the OSC and its processing are pivotal. For instance, a high degree of crystallinity provides a more efficient blocking against ion diffusion. Our group has already demonstrated that BAMS can produce excellent coatings based on blends of reference OSCs for achieving outperforming EGOFETs with exceptional robustness. $^{[20,41]}$

As mentioned before, the best film found for the EGOFET configuration has been obtained here using the formulation DPTTA:PS 10k (1:3) (4). Concerning the aqueous electrolyte media, ultrapure water was used to study the transistor operation and its stability in 
this media. Further, a $0.5 \mathrm{M} \mathrm{NaCl}$ electrolyte aqueous solution was also tested to demonstrate the potential application of these EGOFETs in a harsher media compatible with real sensing applications. As expected, the EGOFET results exhibited clearly p-type semiconductor behavior in both media in a $V_{G S}$ windows ranging from 0.9 to $-0.3 \mathrm{~V}$ (Figure 4a). The corresponding output characteristics measured in ultrapure water and the $0.5 \mathrm{M} \mathrm{NaCl}$ solution are also displayed in Figure 4b and Figure S4, respectively. For both media, a little anticlockwise hysteresis is observed. The presence of hysteresis suggests the presence of some traps on top of the semiconductor surface probably caused by the surface roughness. Noticeably, no negative shifting of the threshold voltage was observed in the $0.5 \mathrm{M} \mathrm{NaCl}$ solution when compared with that in ultrapure water.
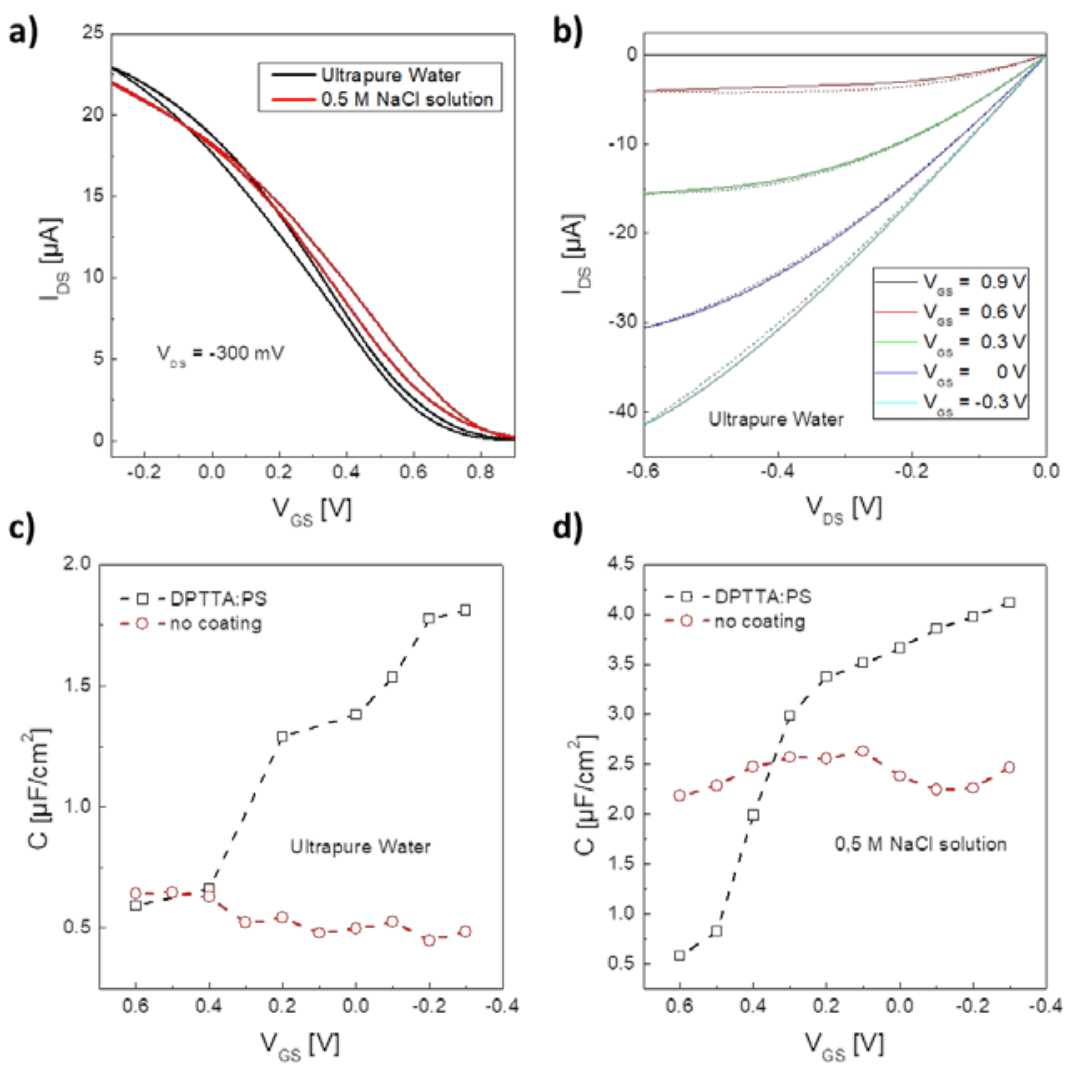

Figure 4. a) EGOFET transfer characteristics of a DPTTA:PS 10k (1:3) thin film, in water and in $\mathrm{NaCl} 0.5 \mathrm{M}$ and (b) output characteristics. c) and (d) are the impedance spectroscopy measurements carried out to obtain the capacitance used to calculate the mobility. 
In order to calculate the EGOFET mobility $\left(\mu_{E G O F E T}\right)$, we performed electrochemical impedance spectroscopy measurements to extract the dielectric capacitance $(C)$. These measurements were carried out using source and drain electrodes short-circuited as counterelectrode meanwhile a Pt wire immersed in the media was acting as working electrode. ${ }^{\text {[42] }}$ Capacitance response was recorded at different DC voltages spanning from 0.6 to $-0.3 \mathrm{~V}$ in order to resemble the gate voltage window employed during transfer characteristic. The $C-V_{G S}$ plots extracted at a frequency of $10 \mathrm{~Hz}$ are displayed in Figure 4c and 4d. The $C$ trend shows the transition from OFF to ON state for the DPTTA:PS coated device, whereas this behavior was not observed in coating-free substrates. A capacitance of $1.2 \mu \mathrm{F} / \mathrm{cm}^{2}$ and $3.4 \mu \mathrm{F} / \mathrm{cm}^{2}$ was found when ultrapure water and a $0.5 \mathrm{M} \mathrm{NaCl}$ aqueous solution were used, respectively. These values are comparable to other reported for thin films of different semiconductors such as dibenzo-tetrathiafulvalene, poly(3-hexylthiophiene) or pentacene. ${ }^{[20,24,43]}$ The corresponding mobility $\left(\mu_{E G O F E T}\right)$ and threshold voltage $\left(V_{T H}\right)$ values extracted for the EGOFET are summarized in Table 2 . As expected, the extracted $\mu_{E G O F E T}$ is smaller than the $\mu$ found for the OFET due to the high dielectric constant of the media. ${ }^{[44]}$ However, the drop of $\mu$ is not even one order of magnitude lower compared to the back-gated OFET, in contrast to what is commonly encountered in other OSC thin films. ${ }^{[45]}$ In fact, the EGOFET mobility found for this DPTTA OSC film is among the best values found for this type of devices.

Table 2. EGOFET parameters found for DPTTA formulation 4. $\mu_{E G O F E T}$ and $V_{T H}$ values are averaged from 16 devices and 6 devices for water and $\mathrm{NaCl}$, respectively.

\begin{tabular}{llllll}
\hline Media & $\mu_{\text {EGOFET }}\left[\mathrm{cm}^{2} / \mathrm{V} \cdot \mathrm{s}\right]$ & $V_{T H}[\mathrm{~V}]$ & $\tau_{\text {ON }}[\mathrm{ms}]$ & $\tau_{\text {OFF }}[\mathrm{ms}]$ & Max. P.S. $[\mu \mathrm{V}]$ \\
\hline Ultrapure Water & $0.12 \pm 0.03$ & $1.0 \pm 0.1$ & 9.4 & 4.7 & 200 \\
NaCl 0.5M & $0.03 \pm 0.01$ & $1.0 \pm 0.3$ & 1.3 & 1.4 & 500 \\
\hline
\end{tabular}


EGOFETs are promising candidates for sensing platforms due to their ability to easily transduce a chemical or biological signal into a measurable electric current. ${ }^{[45-47]}$ Therefore, it is crucial to know the lowest voltage shift that it can detect. This signal is directly proportional to the detection limit of the desired analyte. Hence, to obtain the potentiometric sensitivity (P.S.) of the EGOFET, square pulses of $V_{G S}$ have been applied to the device and the corresponding output current has been recorded (Figure 5a and 5b). Detectable responses to voltage steps as low as $200 \mu \mathrm{V}$ have been successfully recorded for water-gated samples. However, for samples gated using $0.5 \mathrm{M} \mathrm{NaCl}$ the lowest detectable value was $500 \mu \mathrm{V}$ because of the higher electrical noise found for this media.
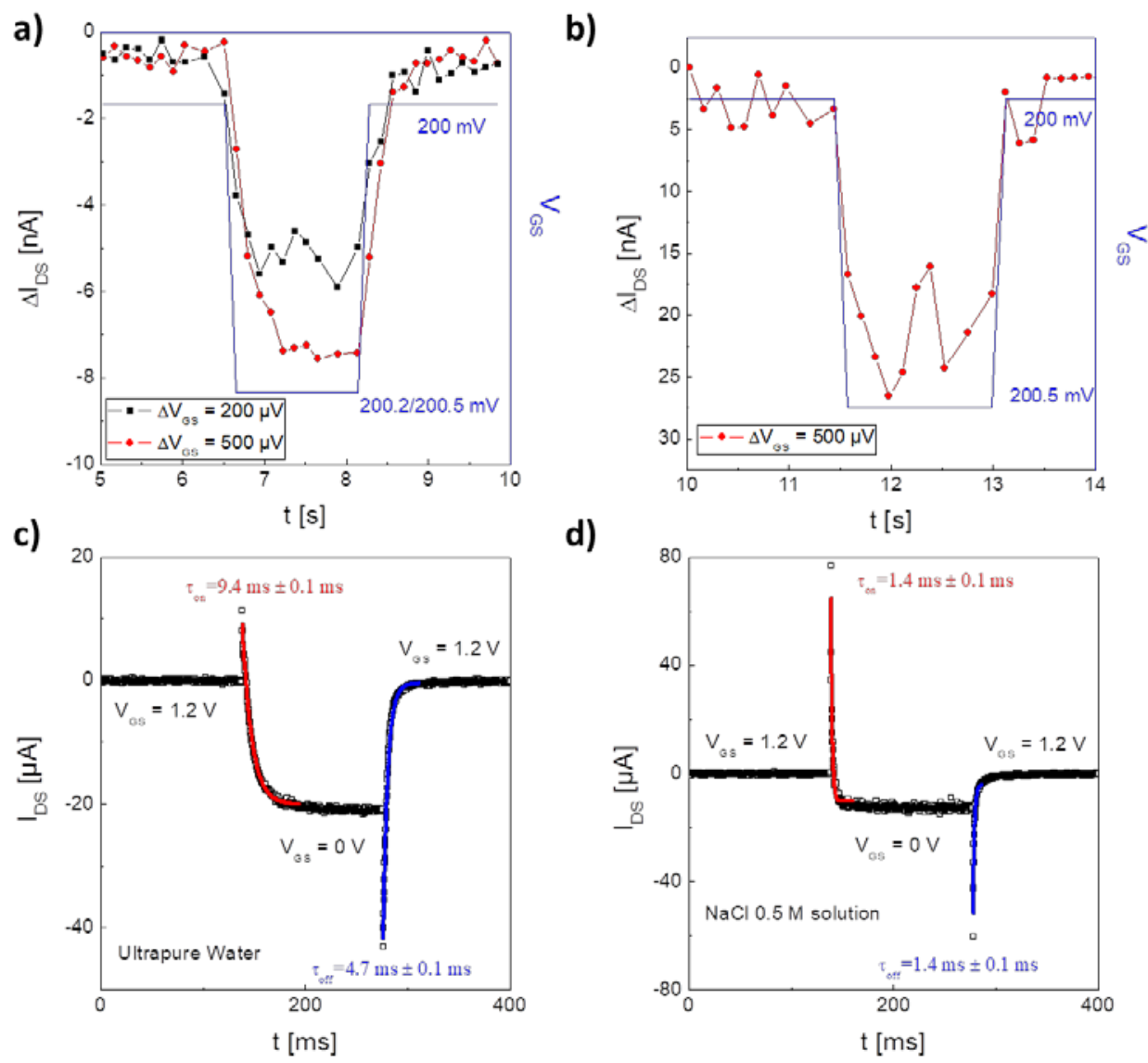

Figure 5. Potentiometric sensitivity of the EGOFETs measured when (a) ultrapure water and (b) $0.5 \mathrm{M} \mathrm{NaCl}$ aqueous solution is used as electrolyte dielectric. Switching speed measurements with the exponential fit used to obtain the turn on and off time using (c) ultrapure water and (d) $0.5 \mathrm{M} \mathrm{NaCl}$. In all these measurements the $V_{D S}$ was $300 \mathrm{mV}$. 
As important as the potentiometric sensitivity is the speed of the response that would permit to detect punctual fluctuations of a chemical/biological signal. To obtain the EGOFET switching speed $(\tau)$, a square voltage $\left(V_{G S}\right)$ pulse from 1.2 to $0 \mathrm{~V}$ to switch on and vice versa to switch off has been applied while the current was monitored with an integration time of $250 \mu$ s (Figure 5c and 5d). The channel formation and disruption have been fitted through an exponential formula $\left(I_{D S} \propto \mathrm{e}^{ \pm(t / \tau)}\right)$ to extract their characteristic time response, i.e. $\tau_{O N}$ and $\tau_{\mathrm{OFF} .}{ }^{[48]}$ The switching speed values indicate a fairly symmetric and quick turn on and off of the EGOFET in both media, values of which are displayed in Table 2.

a)

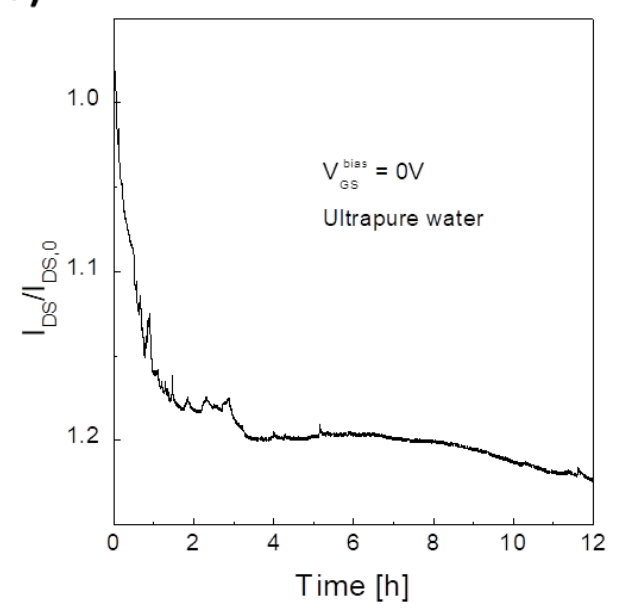

b)

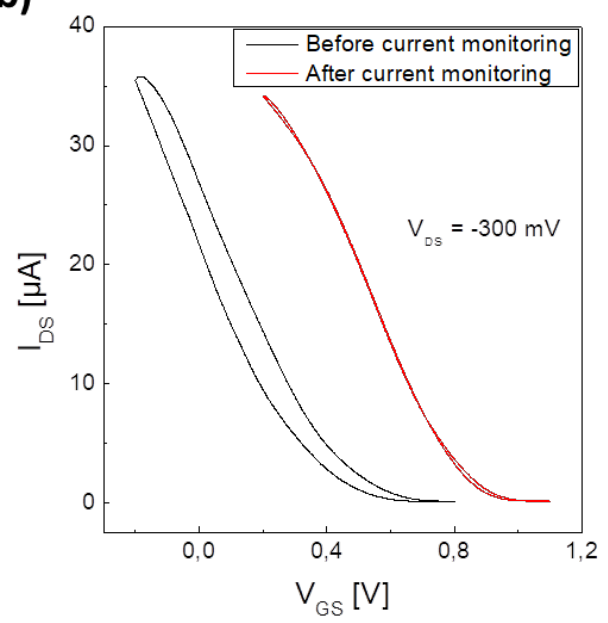

Figure 6. a) Real-time current monitoring of DPTTA EGOFET. b) Transfer characteristics measured before and after the current monitoring to show the stability of the OFET after 12 hours of continuous electrical stress in water.

Stability measurements represent the last figure of merit for depicting the quality of an EGOFET device. Figure 6 displays real-time current monitoring which consists on applying two constant potentials, namely $V_{D S}=300 \mathrm{mV}$ and $V_{G S}=0 \mathrm{~V}$, while measuring the corresponding source-drain current. This kind of electrical tests are usually desirable if the 
platform is envisioned for monitoring the presence of a certain analyte in a continuous flow, i.e., a water pollutant, a specific biomolecule, etc. ${ }^{[49]}$ OFETs fabricated with formulation 4 have demonstrated to be stable in ultrapure water. As displayed in Figure 6, the $I_{D S}$ current increases quickly the first 2 hours and then it reaches a stable plateau with a current $20 \%$ higher compared with its initial current. Furthermore, transfer characteristics were recorded before and after the stability experiment (Figure 6b) and only a reduction of hysteresis and a positive shift of the threshold voltage were the main effect observed, which would explain the increase of the current due to an increase of the effective electric field $\left(V_{G S \text {,eff }}=\left|V_{G S^{-}} V_{T H}\right|\right)$. Unfortunately, with the $\mathrm{NaCl} 0.5 \mathrm{M}$ solution the devices were deteriorating more quickly in a time scale of few minutes (Figure S5), which is probably caused by the penetration of ions into the bulk OSC.

All these EGOFET results unequivocally attest the efficiency of combining OSC:PS blends with BAMS for achieving superior EGOFET performance.

\section{Conclusions}

In conclusion, it was demonstrated for the first time that thin films of the hardly explored DPTTA OSC can be prepared from solution employing a high throughput technique that results in excellent performing devices. A series of DPTTA:PS blend thin films with different OSC:PS ratios and different PS molecular weights have been deposited successfully by utilizing the BAMS technique using a hydrophobic PTFE bar. As confirmed by XRPD data, all the films exhibit the same crystal structure which does not correspond to the previously reported single crystal. The OFET devices fabricated with these films exhibited state-of-theart performance with an average mobility around $1 \mathrm{~cm}^{2} / \mathrm{V} \cdot \mathrm{s}$. Furthermore, the films were additionally tested as active layers in EGOFETs also fulfilling the best characteristics of these reported devices, such as $\mu_{E G O F E T}>0.1 \mathrm{~cm}^{2} / \mathrm{V} \cdot \mathrm{s}$, potentiometric sensitivity $\sim 200 \mu \mathrm{V}$, time 
response $\sim 9 \mathrm{~ms}$ and long term stability in ultrapure water. This work does not only further support the strategy of combining OSC:PS blends with BAMS as a powerful route for achieving high performing devices, but also indicates that DPTTA can become a promising OSC for the next device generation

\section{Experimental Section}

Materials: Meso-tetrathia[22]annulene[2,1,2,1] (DPTTA) was synthesized as reported in reference [20]. Polystyrene $\mathrm{M}_{\mathrm{w}}=3 \mathrm{k}, 10 \mathrm{k}$ and $100 \mathrm{k} \mathrm{g} / \mathrm{mol}$ (namely PS 3k, PS 10k and PS $100 \mathrm{k}$, respectively) were purchased from Sigma-Aldrich and were used without further purification. 2,3,4,5,6-Pentafluorothiophenol (PFBT) was also purchased from Sigma-Aldrich. Formulation preparation: Optimized inks were prepared in a ratio of DPTTA:PS 1:2 for PS 10k and PS 100k and 1:3 for PS 3k and PS 10k. This last formulation was used to fabricate the active layers for EGOFETs. Solution final concentration (DPTTA+PS) was $22.6 \mathrm{mg} / \mathrm{ml}$ when PS 10k and PS 100k in 1:2 ratio were used, and $26 \mathrm{mg} / \mathrm{ml}$ for PS 3k and $20 \mathrm{mg} / \mathrm{ml}$ for PS $10 \mathrm{k}$ when they were mixed in a 1:3 ratio with the OSC. The solvent in all the cases was anhydrous chlorobenzene (CB). Amber vials were used to protect the formulation against possible harmful effects of light.

Substrate fabrication: Highly n-doped silicon with $200 \mathrm{~nm} \mathrm{SiO}{ }_{2}$ was purchased from SiMat. Fabrication of source (S) and drain (D) contacts was performed by photolithography by using a Micro-writer from Durham Magneto Optics LTD. Afterwards chromium and gold metal layers were deposited by thermal evaporation at $2 \times 10^{-6}$ mbar using an Evaporation System Auto 306 from Boc Edwards. Channel length (L) was fixed to $100 \mu \mathrm{m}$ while channel widths (W) were $10 \mathrm{~mm}(\mathrm{~W} / \mathrm{L}=100)$ and $69 \mathrm{~mm}(\mathrm{~W} / \mathrm{L}=690)$ for back-gated (BG) OFETs and EGOFETs, respectively. After the lift off process, the samples were cleaned by sonication in acetone and isopropanol (IPA) three times each for 15 minutes. In order to improve the 
performance of the OFETs, S and D contacts were functionalized with a self-assembled monolayer of PFBT by exposing substrates to ultraviolet ozone for 25 minutes followed by their immersion in a 15 mM PFBT solution in IPA for 15 minutes. Afterwards, the substrates were rinsed with IPA and kept in air for at least 2 days in order to recover the original properties of $\mathrm{SiO}_{2}$ surface.

Active layer fabrication: Blend coating was performed using the Bar-Assisted Meniscus Shearing (BAMS) technique as described earlier. ${ }^{[4]}$ However, in this work, instead of a metal bar, a polytetrafluoroethylene (PTFE) bar was used. Prior the fabrication, the ink was kept in the hotplate for at least two hours to completely solubilize DPTTA. The bar speed was 10 $\mathrm{mm} / \mathrm{s}$ and the hotplate temperature was $105^{\circ} \mathrm{C}$.

Film morphological characterization: Optical microscope images were taken with an Olympus BX51 equipped with a polarizer and analyzer. Atomic force microscope (AFM) images were obtained working with a 5100 SPM system from Agilent technologies in tapping mode and the images were analyzed using Gwyddion 2.47 software. X-ray powder diffraction (XRPD) measurements were carried out with a PANalytical X'PERT PRO diffractometer MRD.

Electrical measurements: Electrical measurements for both OFETs and EGOFETs were carried out in air and dark conditions using an Agilent B1500A semiconductor device analyzer connected to the samples with a Karl SÜSS probe station. For the BG, the highlydoped silicon was used as a gate. For the EGOFETs, a pool fabricated with polydimethylsiloxane (PDMS) was used to hold $100 \mu$ l of ultrapure water (or $0.5 \mathrm{M} \mathrm{NaCl}$ aqueous solution) and a platinum wire was inserted into the pool acting as gate electrode.

OFET parameters extraction: Field-effect mobility $\left(\mu_{F E, s a t}\right)$ was extracted in saturation regime using the slope (m) of the linear fit of $\left(\left|I_{D S}\right|\right)^{1 / 2}$ vs. $V_{G S}$. Afterwards, the following formula was applied: 


$$
\mu_{F E, s a t}=m \cdot \frac{2 \cdot L}{W} \cdot \frac{1}{C}
$$

where $L$ and $W$ stands for channel length and width, respectively, and $C$ stands for capacitance. Threshold voltage $\left(V_{T H}\right)$ was calculated with the following equation:

$$
V_{T H}=-\frac{n}{m}
$$

where $n$ stands for the y-intercept of the linear fit. For extracting the subthreshold swing (SS) the following formula was used:

$$
S S=\frac{d\left(\log \left(I_{D S}\right)\right)}{d V_{G S}}
$$

The maximum density of traps was estimated using the following formula extracted from ${ }^{\text {[39] }}$

$$
N_{T}^{\max }=\frac{C_{i}}{q}\left[\frac{q S S \log e}{k_{B} T}-1\right]
$$

where $k_{\mathrm{B}}$ is Boltzmann's constant, $T$ is the temperature, e is the base of the natural logarithm and $q$ is the charge on an electron.

Switching speed measurements were carried out using a Test Script Processing (TSP) embedded in Keithley 2604B.

Electrochemical Impedance Spectroscopy (EIS): Measurements were carried out using a Novocontrol Alpha-AN impedance analyzer equipped with POT/GAL 30 V/2 A electrochemical interface.

\section{Acknowledgements}

The authors thank the ERC StG2012-306826 e-GAMES project, the DGI (Spain) with project, FANCY CTQ2016-80030-R, the Generalitat de Catalunya (2014-SGR-17), the Networking Research Center on Bioengineering, Biomaterials and Nanomedicine (CIBER-BBN), and the Spanish Ministry of Economy and Competitiveness, through the "Severo Ochoa” Programme for Centres of Excellence in R\&D (SEV-2015-0496). Q.Z. acknowledges the China 
Scholarship Council, the National Natural Science Foundation (NSF) of China (11404266), and the Fundamental Research Funds for the Central Universities (Grant No. XDJK2014C081). F.L. gratefully acknowledges the “Juan de la Cierva” programme. A.C. and Q.Z. are enrolled in the Materials Science PhD Program of Universitat Autònoma de Barcelona.

\section{References}

[1] M. Irimia-Vladu, Chem. Soc. Rev. 2014, 43, 588.

[2] M. Magliulo, K. Manoli, E. Macchia, G. Palazzo, L. Torsi, Adv. Mater. 2015, 27, 7528.

[3] W. Lee, D. Kim, J. Rivnay, N. Matsuhisa, T. Lonjaret, T. Yokota, H. Yawo, M. Sekino, G. G. Malliaras, T. Someya, Adv. Mater. 2016, 28, 9722.

[4] S. G. Higgins, B. V. O. Muir, G. Dell’Erba, A. Perinot, M. Caironi, A. J. Campbell, Adv. Electron. Mater. 2016, 2, 1500272.

[5] B. Fraboni, A. Fraleoni-Morgera, Y. Geerts, A. Morpurgo, Adv. Funct. Mater. 2016, 26, 2229.

[6] R. S. Ashraf, I. Meager, M. Nikolka, M. Kirkus, M. Planells, B. C. Schroeder, S. Holliday, M. Hurhangee, C. B. Nielsen, H. Sirringhaus, I. McCulloch, J. Am. Chem. Soc. 2015, 137, 1314.

[7] Y. Yamashita, F. Hinkel, T. Marszalek, W. Zajaczkowski, W. Pisula, M. Baumgarten, H. Matsui, K. Müllen, J. Takeya, Chem. Mater. 2016, 28, 420.

[8] M. Mas-Torrent, C. Rovira, Chem. Soc. Rev. 2008, 37, 827.

[9] I. Temiño, F. G. Del Pozo, M. R. Ajayakumar, S. Galindo, J. Puigdollers, M. MasTorrent, Adv. Mater. Technol. 2016, 1, 1600090.

[10] J. Smith, W. Zhang, R. Sougrat, K. Zhao, R. Li, D. Cha, A. Amassian, M. Heeney, I. McCulloch, T. D. Anthopoulos, Adv. Mater. 2012, 24, 2441. 
[11] Y. Yuan, G. Giri, A. L. Ayzner, A. P. Zoombelt, S. C. B. Mannsfeld, J. Chen, D. Nordlund, M. F. Toney, J. Huang, Z. Bao, Nat. Commun. 2014, 5, 3005.

[12] A. F. Paterson, N. D. Treat, W. Zhang, Z. Fei, G. Wyatt-Moon, H. Faber, G. Vourlias, P. A. Patsalas, O. Solomeshch, N. Tessler, M. Heeney, T. D. Anthopoulos, Adv. Mater. 2016, 28, 7791.

[13] Y. Diao, L. Shaw, Z. Bao, S. C. B. Mannsfeld, Energy Environ. Sci. 2014, 7, 2145.

[14] B. R. Hamilton, J. Smith, S. Ogier, M. Heeney, J. E. Anthony, I. Mcculloch, J. Veres, D. D. C. Bradley, T. D. Anthopoulos, Adv. Mater. 2009, 21, 1166.

[15] A. D. Scaccabarozzi, N. Stingelin, J. Mater. Chem. A 2014, 2, 10818.

[16] M. R. Niazi, R. Li, E. Qiang Li, A. R. Kirmani, M. Abdelsamie, Q. Wang, W. Pan, M. M. Payne, J. E. Anthony, D.-M. Smilgies, S. T. Thoroddsen, E. P. Giannelis, A. Amassian, Nat. Commun. 2015, 6, 8598.

[17] J. Smith, R. Hamilton, I. McCulloch, N. Stingelin-Stutzmann, M. Heeney, D. D. C. Bradley, T. D. Anthopoulos, J. Mater. Chem. 2010, 20, 2562.

[18] F. G. del Pozo, S. Fabiano, R. Pfattner, S. Georgakopoulos, S. Galindo, X. Liu, S. Braun, M. Fahlman, J. Veciana, C. Rovira, X. Crispin, M. Berggren, M. Mas-Torrent, Adv. Funct. Mater. 2016, 26, 2379.

[19] S. Galindo, A. Tamayo, F. Leonardi, M. Mas-Torrent, Adv. Funct. Mater. 2017, 27, 1700526.

[20] F. Leonardi, S. Casalini, Q. Zhang, S. Galindo, D. Gutiérrez, M. Mas-Torrent, Adv. Mater. 2016, 28, 10311.

[21] K. Singh, A. Sharma, J. Zhang, W. Xu, D. Zhu, Chem. Commun. 2011, 47, 905.

[22] Y. Qin, J. Zhang, X. Zheng, H. Geng, G. Zhao, W. Xu, W. Hu, Z. Shuai, D. Zhu, Adv. Mater. 2014, 26, 4093.

[23] Y. Qin, C. Cheng, H. Geng, C. Wang, W. Hu, W. Xu, Z. Shuai, D. Zhu, Phys. Chem. Chem. Phys. 2016, 18, 14094. 
[24] L. Kergoat, L. Herlogsson, D. Braga, B. Piro, M. C. Pham, X. Crispin, M. Berggren, G. Horowitz, Adv. Mater. 2010, 22, 2565.

[25] J. Kofler, K. Schmoltner, A. Klug, E. J. W. List-Kratochvil, Appl. Phys. Lett. 2014, 104, 193305.

[26] M. Y. Mulla, E. Tuccori, M. Magliulo, G. Lattanzi, G. Palazzo, K. Persaud, L. Torsi, Nat. Commun. 2015, 6, 6010.

[27] K. Zhao, O. Wodo, D. Ren, H. U. Khan, M. R. Niazi, H. Hu, M. Abdelsamie, R. Li, E. Q. Li, L. Yu, B. Yan, M. M. Payne, J. Smith, J. E. Anthony, T. D. Anthopoulos, S. T. Thoroddsen, B. Ganapathysubramanian, A. Amassian, Adv. Funct. Mater. 2016, 26, 1737.

[28] B. R. Hamilton, J. Smith, S. Ogier, M. Heeney, J. E. Anthony, I. Mcculloch, J. Veres, D. D. C. Bradley, T. D. Anthopoulos, Adv. Mater. 2009, 21, 1166.

[29] A. Kumar, M. A. Baklar, K. Scott, T. Kreouzis, N. Stingelin-Stutzmann, Adv. Mater. 2009, 21, 4447.

[30] A. Kumar, M. A. Baklar, K. Scott, T. Kreouzis, N. Stingelin-Stutzmann, Adv. Mater. 2009, 21, 4447.

[31] G. Giri, S. Park, M. Vosgueritchian, M. M. Shulaker, Z. Bao, Adv. Mater. 2014, 26, 487.

[32] A. Brillante, I. Bilotti, R. G. Della Valle, E. Venuti, S. Milita, C. Dionigi, F. Borgatti, A. N. Lazar, F. Biscarini, M. Mas-Torrent, N. S. Oxtoby, N. Crivillers, J. Veciana, C. Rovira, M. Leufgen, G. Schmidt, L. W. Molenkamp, CrystEngComm 2008, 10, 1899.

[33] R. Pfattner, M. Mas-Torrent, I. Bilotti, A. Brillante, S. Milita, F. Liscio, F. Biscarini, T. Marszalek, J. Ulanski, A. Nosal, M. Gazicki-Lipman, M. Leufgen, G. Schmidt, W. M. Laurens, L. W. Molenkamp, V. Laukhin, J. Veciana, C. Rovira, Adv. Mater. 2010, 22, 4198.

[34] R. Pfattner, S. T. Bromley, C. Rovira, M. Mas-Torrent, Adv. Funct. Mater. 2016, 26, 
2256.

[35] M. Mas-Torrent, C. Rovira, Chem. Rev. 2011, 111, 4833.

[36] S. Scheinert, G. Paasch, M. Schrödner, H. K. Roth, S. Sensfuß, T. Doll, J. Appl. Phys. 2002, 92, 330.

[37] A. Wang, I. Kymissis, V. Bulović, A. I. Akinwande, IEEE Trans. Electron Devices 2006, 53, 9.

[38] N. I. Craciun, Y. Zhang, A. Palmaerts, H. T. Nicolai, M. Kuik, R. J. P. Kist, G. A. H. Wetzelaer, J. Wildeman, J. Vandenbergh, L. Lutsen, D. Vanderzande, P. W. M. Blom, J. Appl. Phys. 2010, 107, 124504.

[39] M. H. Yoon, C. Kim, A. Facchetti, T. J. Marks, J. Am. Chem. Soc. 2006, 128, 12851.

[40] E. G. Bittle, J. I. Basham, T. N. Jackson, O. D. Jurchescu, D. J. Gundlach, Nat. Commun. 2015, 7, 10908.

[41] Q. Zhang, F. Leonardi, S. Casalini, I. Temiño, M. Mas-Torrent, Sci. Rep. 2016, 6, 39623.

[42] S. H. Kim, K. Hong, W. Xie, K. H. Lee, S. Zhang, T. P. Lodge, C. D. Frisbie, Adv. Mater. 2013, 25, 1822.

[43] T. Cramer, A. Kyndiah, M. Murgia, F. Leonardi, S. Casalini, F. Biscarini, Appl. Phys. Lett. 2012, 100, 143302.

[44] J. Veres, S. D. Ogier, S. W. Leeming, D. C. Cupertino, S. M. Khaffaf, Adv. Funct. Mater. 2003, 13, 199.

[45] O. Knopfmacher, M. L. Hammock, A. L. Appleton, G. Schwartz, J. Mei, T. Lei, J. Pei, Z. Bao, Nat. Commun. 2014, 5, 2954.

[46] S. Casalini, F. Leonardi, T. Cramer, F. Biscarini, Org. Electron. 2013, 14, 156.

[47] T. Cramer, B. Chelli, M. Murgia, M. Barbalinardo, E. Bystrenova, D. M. de Leeuw, F. Biscarini, Phys. Chem. Chem. Phys. 2013, 15, 3897.

[48] D. Khodagholy, M. Gurfinkel, E. Stavrinidou, P. Leleux, T. Herve, S. Sanaur, G. G. 
Malliaras, Appl. Phys. Lett. 2011, 99, 163304.

[49] A. Campana, T. Cramer, D. T. Simon, M. Berggren, F. Biscarini, Adv. Mater. 2014, 26, 3874. 


\section{Supporting Information}

State-of-the-art performing organic field-effect transistors with a solid and aqueous dielectric based on a solution sheared sulfur-bridged annulene derivative

Antonio Campos, Qiaoming Zhang, M. R. Ajayakumar, Francesca Leonardi and Marta MasTorrent*

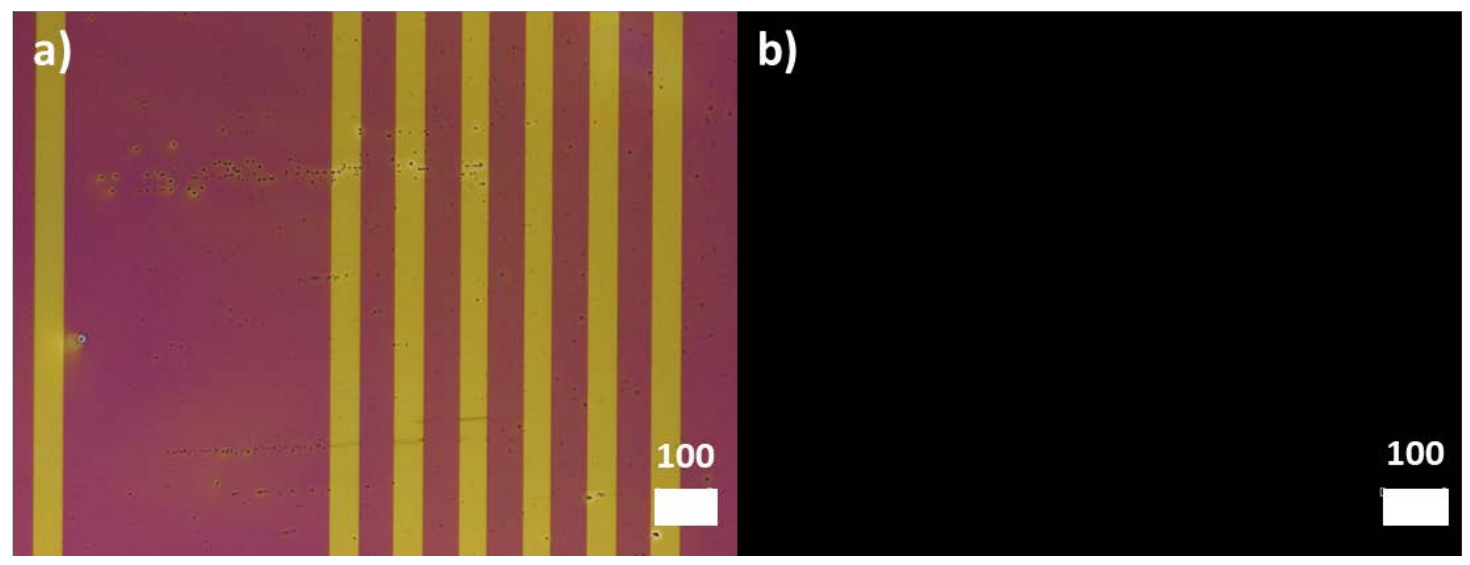

Figure S1. a) Optical and (b) polarized optical microscope images of films deposited with a metal bar.

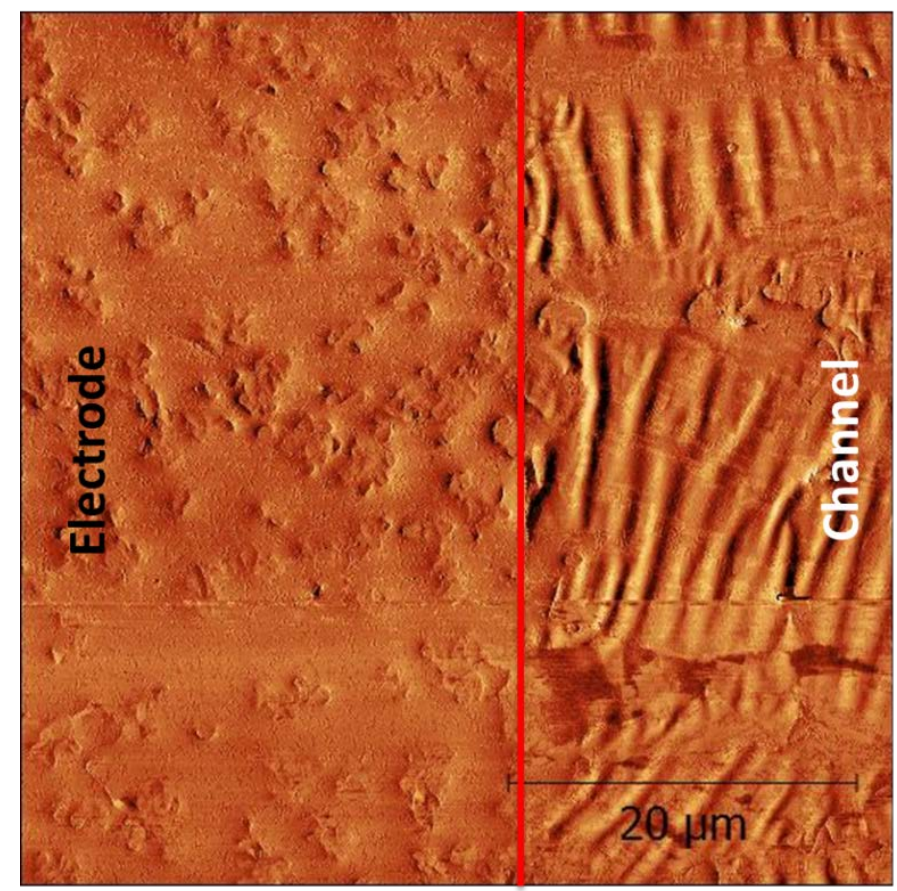

Figure S2. Phase AFM image of sample 4. No significant phase differences can be observed between the channel and the electrodes. 


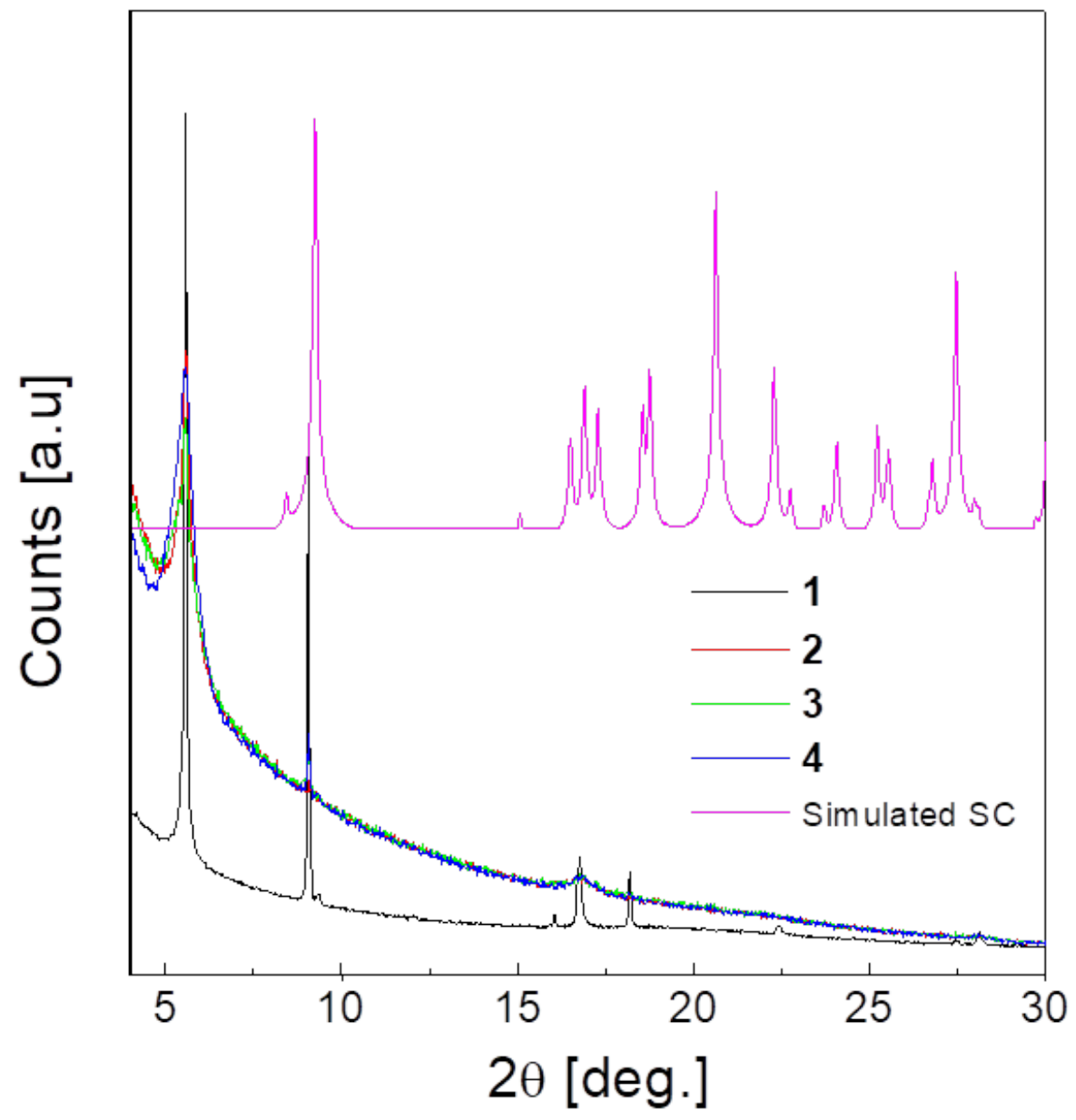

Figure S3. X-ray powder diffraction of the DPTTA/PS films fabricated. 
a)

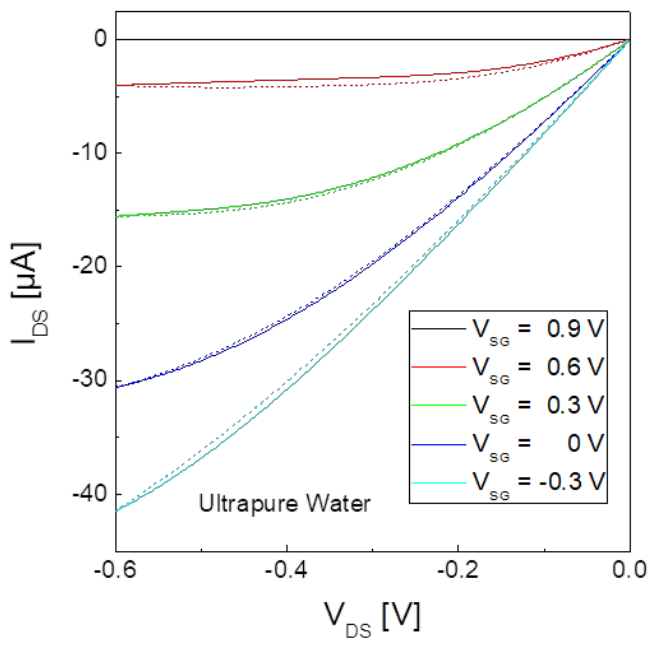

b)

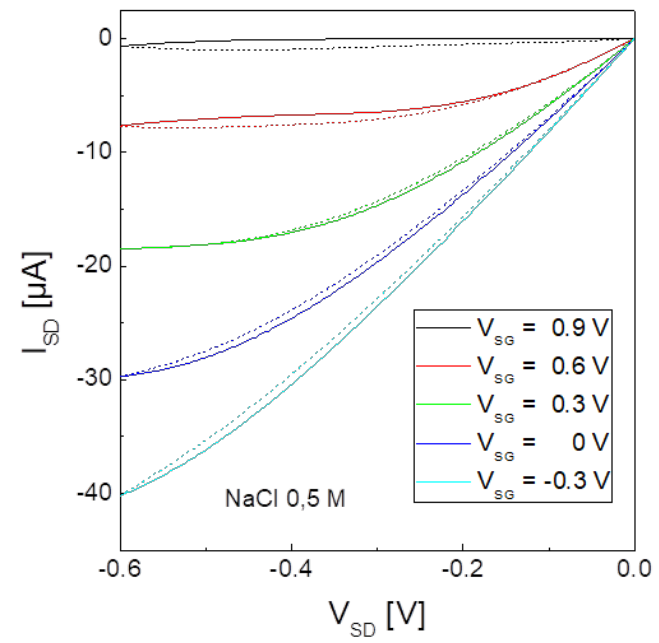

Figure S4. Output characteristics of the EGOFETs fabricated with formulation 4 using (a) ultrapure water and (b) $\mathrm{NaCl} 0.5 \mathrm{M}$ as dielectric. 


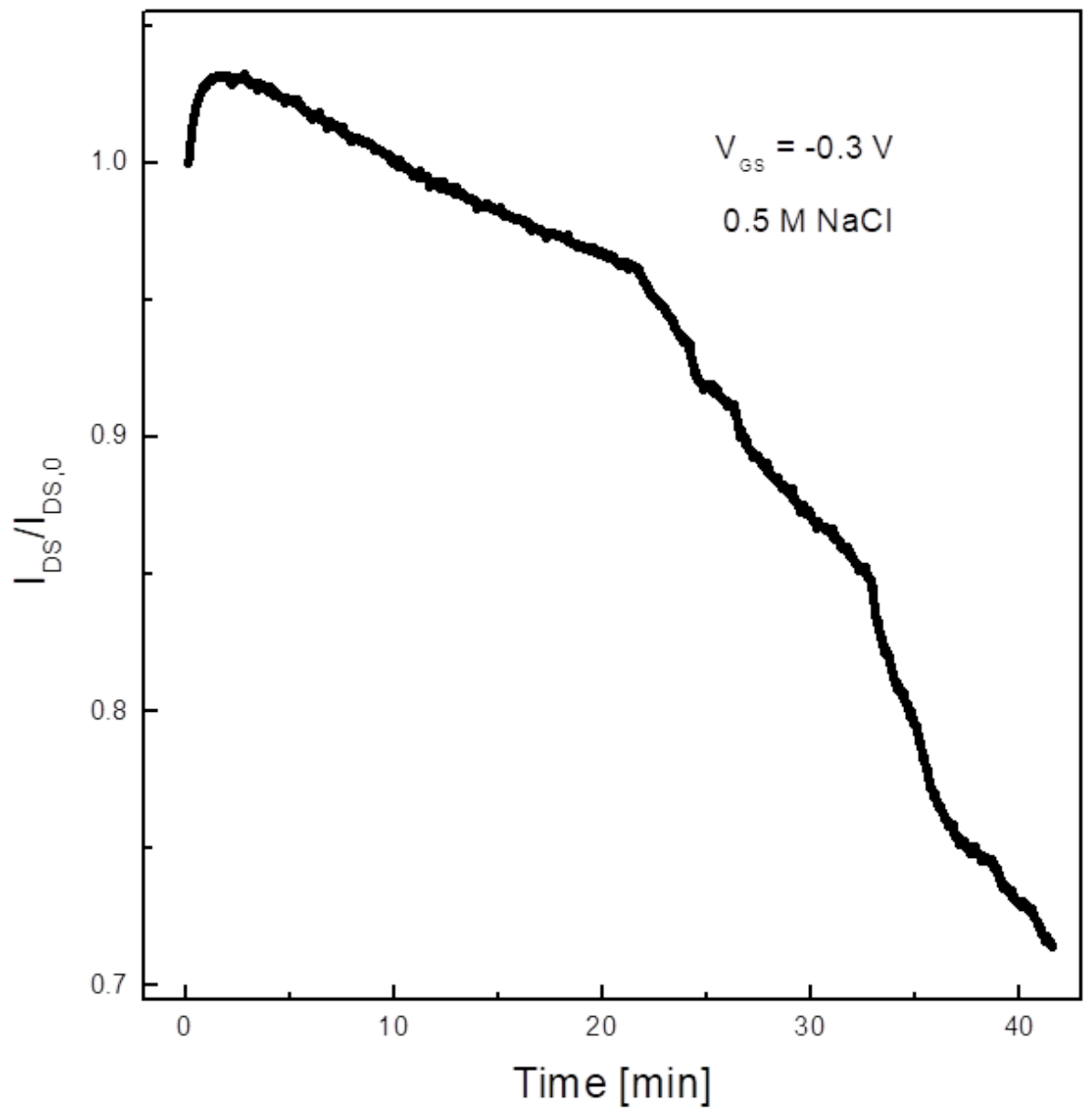

Figure S5. Real-time current monitoring of DPTTA EGOFET in $0.5 \mathrm{M} \mathrm{NaCl}$ aqueous solution. 